\title{
PENYULUHAN TEKNIK BERJALAN KAKI YANG BENAR BAGI KELOMPOK LANJUT USIA DI GEREJA KRISTEN INDONESIA NURDIN, JAKARTA
}

\author{
Ignatio Rika Haryono ${ }^{1}$ dan Nawanto A. Prastowo ${ }^{2}$ \\ ${ }^{1}$ Fakultas Kedokteran dan Ilmu Kesehatan, Universitas Katolik Indonesia Atma Jaya \\ Email: rika_haryono@yahoo.com \\ ${ }^{2}$ Fakultas Kedokteran dan Ilmu Kesehatan, Universitas Katolik Indonesia Atma Jaya \\ Email: nawanto2005@gmail.com
}

\begin{abstract}
The prevalence of non-communicable diseases (PTM) is increasing rapidly. PTM prevention can be done by modifying risk factors such as increased physical activity (sports). Aside from prevention, physical activity has a therapeutic effect. However, choosing one type of exercise is apparently not simple. Many factors must be considered including the level of fitness, age, field conditions and others. Another factor to consider is exercise time. For people without the risk of heart attack, physical exercise (sports) can be done at any time. But it needs to be considered if the sport is done outdoors, it should be done at a safe temperature and humidity. For the high risk group for heart attack, the best exercise time is around $15.00-16.00$ which is the highest fibrinolytic activity and the lowest coagulation activity, while the least good time is around $09.00-10.00$ ie the highest coagulation activity and activity the lowest fibrinolytic. Among the many types of exercise, walking is one type of physical activity that is easy and inexpensive. Walking has good health benefits for the elderly. However, walking must be done with the right techniques in order to provide the expected benefits and prevent negative effects, which is minimizing the risks when walking. This counseling is done so that the participants can understand the correct and safe walking technique and do the walking according to the correct technique
\end{abstract}

Keywords: counseling, aerobic exercise, walking technique, elderly, non communicable diseases

\begin{abstract}
ABSTRAK
Prevalensi penyakit tidak menular (PTM) meningkat dengan pesat. Pencegahan PTM dapat dilakukan dengan modifikasi faktor risiko antara lain peningkatan aktivitas fisik (olah raga). Disamping sebagai upaya pencegahan, aktivitas fisik memiliki efek terapi. Namun demikian, memilih satu jenis latihan ternyata tidak sederhana. Banyak faktor harus dipertimbangkan antara lain tingkat kebugaran, usia, kondisi lapangan dan lain-lain. Faktor lain yang perlu dipertimbangkan adalah waktu ber olah raga. Bagi orang tanpa risiko serangan jantung, latihan fisik (olahraga) dapat dilakukan kapan saja. Namun perlu dipertimbangkan bila olahraga dilakukan outdoor, sebaiknya dilakukan pada suhu dan kelembaban yang aman. Bagi kelompok risiko tinggi terhadap serangan jantung, waktu latihan yang paling baik adalah sekitar pukul 15.00 - 16.00 yaitu saat aktivitas fibrinolitik paling tinggi dan aktivitas koagulasi paling rendah, sedangkan waktu yang kurang baik adalah sekitar pukul 09.00 - 10.00 yaitu saat aktivitas koagulasi paling tinggi dan aktivitas fibrinolitik paling rendah. Diantara banyak jenis latihan, jalan kaki adalah salah satu jenis aktivitas fisik yang mudah dan murah. Jalan kaki memiliki manfaat kesehatan yang baik bagi lansia. Namun demikian jalan kaki harus dilakukan dengan teknik yang benar agar memberikan manfaat yang diharapkan dan mencegah efek negatif, yaitu meminimalisir risiko saat melakukan jalan kaki. Penyuluhan ini dilakukan agar para peserta dapat memahami teknik jalan kaki yang benar dan aman serta melakukan jalan kaki sesuai teknik yang benar.
\end{abstract}

Kata kunci: penyuluhan; olahraga aerobik; teknik jalan kaki; lanjut usia; penyakit tidak menular.

\section{PENDAHULUAN}

Non communicable diseases atau penyakit tidak menular (PTM) mengalami peningkatan prevalensi yang sangat pesat. Tingkat mortalitas penyakit tersebut juga sangat tinggi, mencapai $71 \%$ (sekitar 41 juta) dari seluruh penyebab kematian global (GBD 2015 Risk Factors Collaborators, 2016). Terdapat empat PTM yang memiliki tingkat mortalitas paling tinggi yaitu penyakit jantung dan pembuluh darah (17.9 juta per tahun), keganasan ( 9 juta per tahun), penyakit pernafasan (3.9 juta per tahun), dan diabetes melitus (1.6 juta per tahun) (GBD 2015 Risk Factors Collaborators, 2016). Beberapa faktor risiko dihubungkan dengan peningkatan 
prevalensi PTM, yaitu merokok, inaktivitas fisik, pola makan tidak sehat, dan konsumsi alkohol berlebihan (WHO, 2009).

Sebagian besar PTM dapat dicegah. Pencegahan PTM antara lain dapat dapat dilakukan dengan memodifikasi faktor risiko yaitu dengan tidak merokok, pola makan sehat, tidak minum alkohol, dan berolahraga. Salah satu upaya yang cukup sering dilakukan adalah peningkatan aktivitas fisik dengan berolahraga. Meskipun banyak orang bisa melakukan olahraga, namun ternyata olahraga yang dilakukan belum memenuhi kaidah olahraga yang baik, benar, teratur, dan terukur (BBTT) (Pusdatin, Kemkes RI, 2015). Bila olahraga yang dilakukan tidak memenuhi kaidah ini, maka manfaat yang diperoleh kurang atau bahkan tidak ada, bahkan justru bisa menimbulkan efek samping misalnya cedera (Garrick \& Requa, 2003). Untuk itu, beberapa kelompok ahli di bidang olahraga atau yamg berhubungan dengan olahraga menganjurkan atau memberikan rekomendasi tentang peningkatan aktivitas fisik yang baik dan aman. Rekomendasi untuk latihan fisik tersebut kemudian diadopsi oleh badan kesehatan dunia untuk dipergunakan di seluruh dunia. Rekomendasi aktivitas fisik dari WHO adalah intensitas sedang selama 150 menit atau intensitas berat selama 75 menit per minggu (WHO, 2010; U.S. Department of Health and Human Services, 2018). Bentuk aktivitas fisik yang paling baik adalah aerobik antara lain jalan kaki, jogging, berlari, renang, dan bersepeda

Rekomendasi dari WHO tidak serta merta dapat dilaksanakan karena berbagai keterbatasan. Bagi lanjut usia, olahraga intensitas berat sangat tidak aman. Oleh sebab itu, latihan intensitas sedang lebih sesuai bagi kelompok usia lanjut (lansia), karena efek samping minimal. Namun demikian, dengan hanya intensitas sedang, maka pilihan jenis aktivitas fisik menjadi terbatas. Salah satu bentuk latihan fisik yang paling sederhana dan aman bagi lansia adalah jalan kaki. Jalan kaki merupakan aktivitas fisik dasar manusia. Namun demikian tidak sedikit yang belum memahami teknik jalan kaki yang benar. Oleh sebab itu, perlu diadakan penyuluhan tentang teknik jalan kaki yang benar bagi lansia agar lansia dapat memperoleh manfaat berolahraga jalan kaki tanpa harus mengalami cedera.

Komisi Lansia Gereja Kristen Indonesia Nurdin Grogol, Jakarta memiliki kegiatan angterkaitdengan kesehatan yaitu pemeriksaan kesehatan (tekanan darah) secara rutin bagi anggoanya sekali sebulan. Disamping itu, banyak anggota lansia yang melakukan latihan fisik, terutama jalan kaki, meskipun tanpa arahan atau bimbingan. Oleh sebab itu perlu dilakukan penyuluhan dari narasumber yang kompeten terkait teknik jalan kaki yang baik.

\section{METODE PELAKSANAAN}

Ide penyelenggaraan dan topik penyuluhan berasal dari pengurus Komisi Lansia GKI Nurdin. Ide ini kemudian disampaikan kepada narasumber dan setelah disepakati bersama selanjutnya ditentukan jadwal pelaksanaannya.

Kegiatan penyuluhan diselenggarakan di Gereja Kristen Indonesia (GKI) Nurdin, Grogol, Jakarta Barat pada 31 Juli 2018. Peserta penyuluhan adalah anggota Komisi Lansia GKI Nurdin dengan peserta lebih kurang sebanyak 60 orang.

Penyuluhan dilakukan oleh dua narasumber, masing-masing sebagai penyaji dan moderator. Materi disampaikan secara tertulis melalui media powerpoint dan demo Teknik Jalan Kaki Yang Benar oleh atlet nasional melalui video. Waktu untuk penyuluhan lebih kurang 45 menit kemudian dilanjutkan dengan tanya jawab. Seluruh acara berlangsung dalam durasi 2 jam. 


\section{HASIL DAN DISKUSI}

Kegiatan penyuluhan didahului dengan doa bagi panitia dan narasumber oleh salah seorang pengurus komisi lansia. Acara dibuka oleh Ketua Komisi Lansia dan doa bagi seluruh hadirin agar acara berlangsung dengan lancar.

Sesi pertama paparan oleh narasumber pertama (Dr. dr Rika Haryono, SpKO) dengan dipandu narasumber kedua (dr. NA Prastowo, SpKO) sebagai oleh moderator. Materi meliputi Manfaat Jalan Sehat, Teknik Jalan Kaki Yang Benar, Persiapan Jalan, dan Kontra Indikasi. Banyak manfaat Jalan Sehat bagi lansia, antara lain meningkatkan kebugaran jantung paru, menurunkan tekanan darah, memperbaiki profil lipid, menurunkan kadar gula darah, meningkatkan massa otot, memperbaiki lingkup gerak sendi, dan lain-lain.

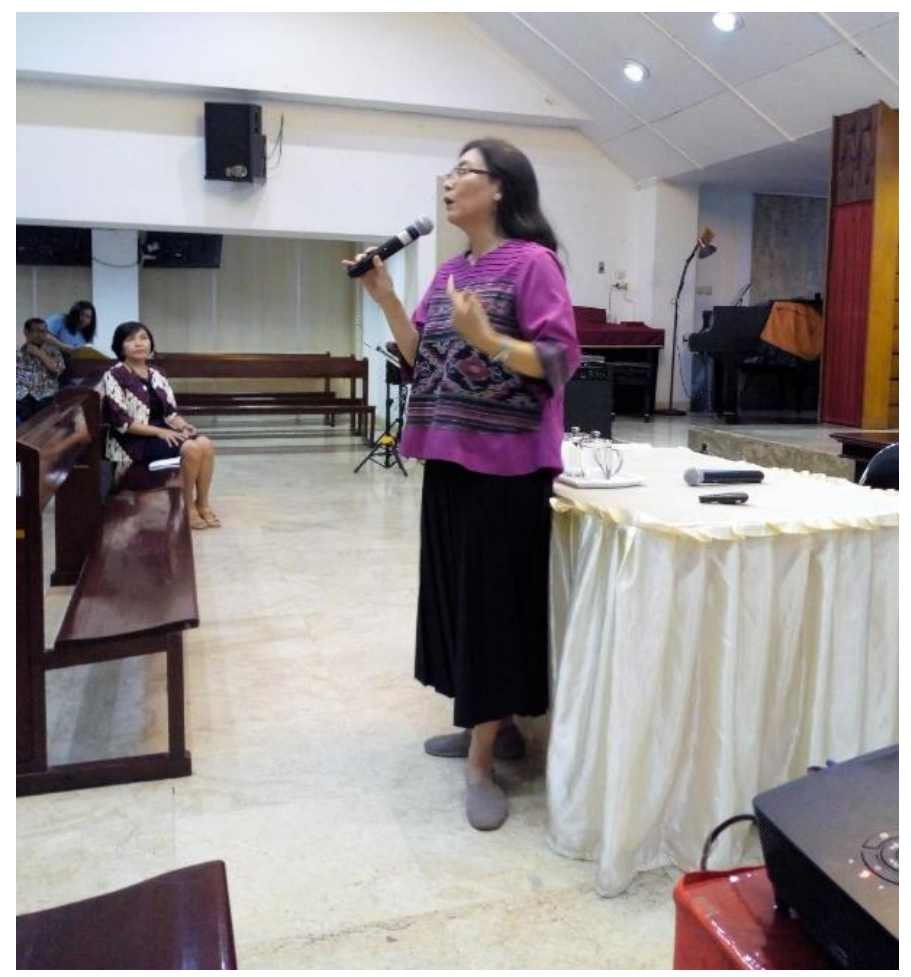

Gambar 1. Narasumber menyampaikan paparan

Teknik Jalan Kaki yang Benar

Teknik Jalan Kaki yang benar harus memenuhi kriteria tertentu, antara lain tubuh tegak (tidak condong ke depan atau ke belakang), pandangan lurus ke depan (bukan ke bawah atau ke atas), lengan terayun bebas dan siku agak fleksi. Pada saat mendarat dimulai dari tumit kemudian ujung jari. Beberapa persiapan wajib dilakukan untuk menghindari cedera dan dehidrasi yaitu dengan memilih lintasan yang baik, permukaan rata dan tidak licin, membawa air minum bila perlu, menggunakan sepatu maupun kostum yang sesuai dan cuaca yang kondusif. Kontra indikasi melakukan jalan kaki pada dasarnya sama dengan olahraga yang lain yaitu bila mengalami cedera yang dapat memburuk bila berjalan, demam, gangguan keseimbangan, tekanan darah meningkat $(>180 / 100 \mathrm{mmHg})$, kadar gula darah tidak normal $(<100 \mathrm{mg} / \mathrm{dL}$ atau $>250 \mathrm{mg} / \mathrm{dL})$, dan cuaca yang tidak kondusif. 


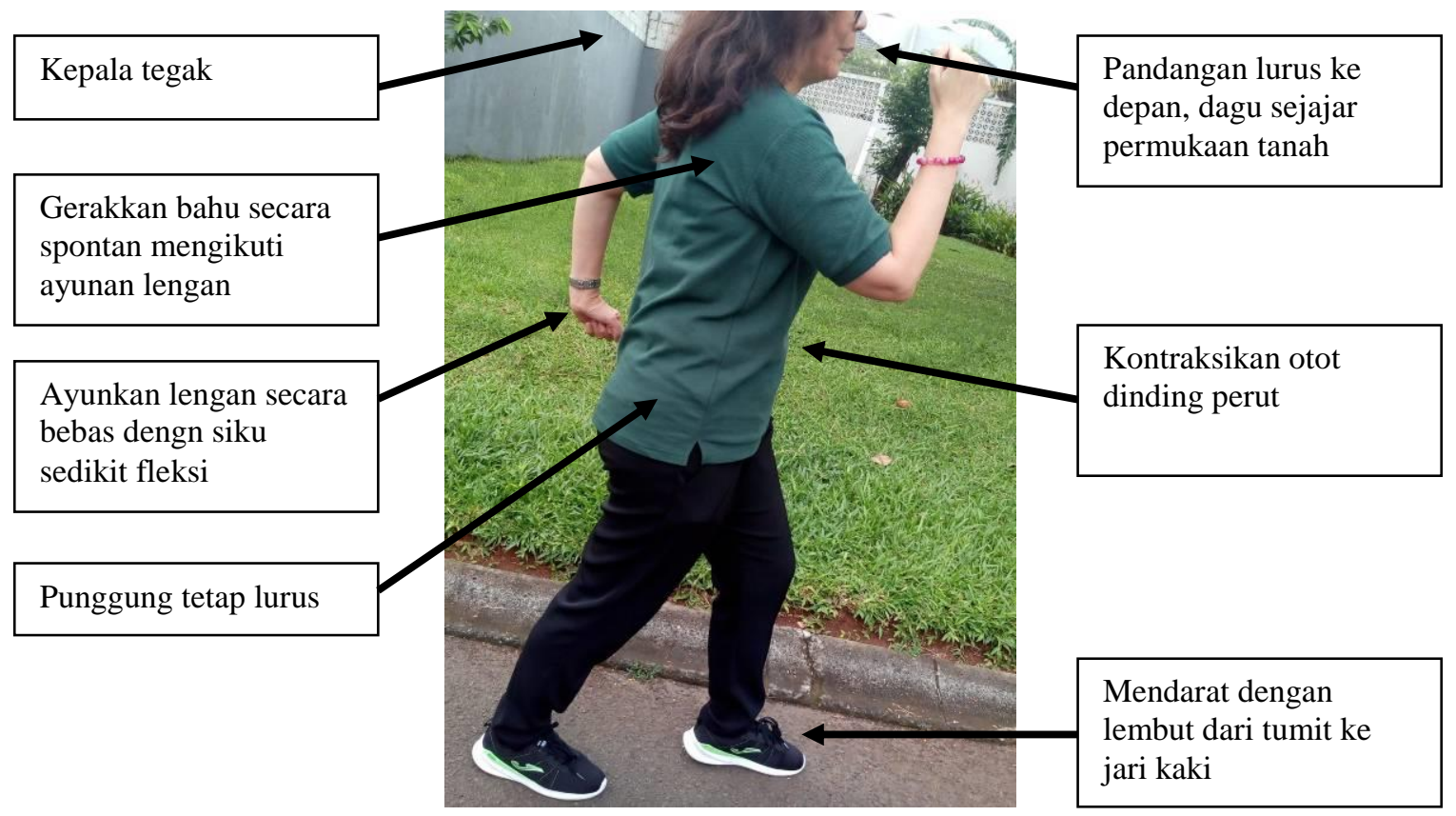

Gambar 2. Teknik Jalan Yang Benar

Sesi kedua adalah pemutaran video tutorial Teknik Jalan Yang Benar oleh seorang atlet jalan cepat nasional. Pada sesi ini seorang atlet nasional jalan cepat menjelaskan teknik jalan kaki yang benar disertai dengan demo.

Sesi ketiga adalah sesi tanya jawab. Pada umumnya seluruh peserta sangat antusias mengikuti penyuluhan. Mereka menyampaikan bahwa materi penyuluhan ini sederhana tetapi sangat bermanfaat. Banyak pertanyaan diajukan oleh peserta yang ternyata dapat menambah informasi yang bermanfaat.

\section{Waktu Latihan atau Berolahraga Terbaik}

Pertanyaan tentang waktu latihan terbaik ini diajukan oleh peserta penyuluhan. Bagi orang tanpa risiko serangan jantung, dapat melakukan olahraga kapan saja. Tetapi perlu dipertimbangkan bila olahraga dilakukan outdoor, sebaiknya dilakukan pada suhu dan kelembaban yang aman. Bagi kelompok risiko tinggi terhadap serangan jantung, waktu latihan yang paling baik adalah sekitar pukul 15.00 - 16.00 dimana aktivitas fibrinolitik paling tinggi dan aktivitas koagulasi paling rendah, sedangkan waktu yang kurang baik adalah sekitar pukul $09.00-10.00$ yaitu saat dimana aktivitas koagulasi paling tinggi dan aktivitas fibrinolitik paling rendah. Dominasi aktivitas koagulasi dapat menimbulkan serangan jantung yang menyebabkan kematian. Beberapa kejadian kematian saat melakukan olahraga sering terjadi pada pagi hari yaitu sekitar pukul $09.00-10.00$ (Szymanski \& Pate, 1994). Selain menurunkan risiko serangan jantung, olahraga sore dapat meningkatkan aktivitas fibrinolisis sehingga menurunkan viskositas darah (Szymanski \& Pate, 1994; Patelis, Karaolanis, Kouvelos, Hart, Metheiken, 2016).

\section{Waktu Makan Sebelum Olahraga}

Seorang peserta juga mengajukan pertanyaan terkait kapan waktu makan terakhir sebelum berolahraga. Pertanyaan ini baik mengingat pengaruh olahraga terhadap sistem pencernaan dan kebutuhan energi selama olahraga. Olahraga intensitas sedang memiliki efek positif terhadap pencernaan, namun olahraga intensitas tinggi justru menimbulkan gangguan pencernaan 
misalnya nyeri ulu hati, mual, muntah, dan nyeri perut. Dalam bentuk ekstrem dapat menyebabkan perdarahan saluran cerna (de Oliveira \& Burini, 2011; Moses, 1990).

Makan juga memengaruhi kinerja selama menjalankan olahraga sehingga intensitas latihan tidak tercapai. untuk mencukupi kebutuhan energi tanpa harus mengganggu kinerja olahraga, maka dianjurkan agar sebaiknya makan besar terakhir minimal 2 atau bahkan 3-4 jam sebelum berolahraga (Morton, Richards, \& Callister, 2005; Pauwels, 2012). Dua jam adalah durasi waktu yang dibutuhkan untuk pengosongan lambung. Namun demikian hal ini sangat individual karena sebagian orang membutuhkan waktu lebih dari dua jam. Melakukan olahraga saat keadaan lambung masih terisi makanan akan menyebabkan rasa kurang nyaman di perut dan olahraga tidak dapat dilanjutkan. Oleh sebab itu setiap individu harus mengetahui durasi pengosongan lambung pada dirinya. Bukan berarti selama menunggu berolahraga dan saat berolahraga tidak diperbolehkan mengonsumsi apapun. Untuk menghindari hipoglikemia dan dehidrasi dapat makan snack mengandung karbohidrat sederhana atau minum sejenis sport drink.

\section{Pengertian Aerobik}

Salah seorang peserta mengajukan pertanyaan mengenai olahraga aerobik. Banyak orang selalu menghubungkan aerobik dengan senam aerobik. Padahal sebenarnya istilah aerobik berhubungan dengan jenis metabolisme. Metabolisme aerobik adalah metabolisme yang membutuhkan dan menggunakan oksigen (aerob) untuk memeroleh energi. Sebaliknya adalah metabolisme anaerob, yaitu metabolisme yang tidak membutuhkan oksigen (anaerob) untuk mendapat energi (Scott, 2005). Metabolisme aerobik sangat berkaitan dengan tingkat intensitas. Semakin rendah intensitas latihan semakin aerob sebaliknya semakin tinggi intensitas latihan semakin kurang aerobik atau semakin anaerob. Oleh sebab itu bila suatu senam aerobik dilakukan dengan intensitas tinggi maka senam tersebut tidak lagi dominan aerobik tetapi dominan anaerob.

Jenis-jenis Latihan atau Olahraga Aerobik.

Latihan atau Olahraga aerobik atau lebih dikenal dengan istilah 'cardio', terdiri dari tiga macam. Olahraga aerobik tipe 1 adalah olahraga aerobik yang intensitasnya dapat dapat sepenuhnya dikendalikan atau disesuaikan dan gerakan-gerakan nya adalah gerakan dasar dan sederhana serta tidak membutuhkan skills khusus. Contoh olahraga aerobik tipe 1 adalah jalan kaki, jogging, lari, dan bersepeda. Olahraga aerobik tipe 1 adalah jenis yang paling sesuai untuk kelompok lanjut usia dan kelompok dengan risiko sedang-tinggi). Apabila seseorang melakukan olahraga aerobik tipe 1, ternyata intensitas latihan terlalu tinggi (ditandai dengan nafas terengahengah) maka orang tersebut dapat menurunkan intensitas dengan cara menurunkan laju atau kecepatannya (ACSM, 2006).

Olahraga aerobik tipe 2 adalah olahraga yang gerakan-gerakannya membutuhkan skills lebih kompleks tetapi intensitas masih dapat dikendalikan. Contoh olahraga aerobik tipe 2 adalah renang dan senam. Olahraga aerobik tipe 3 adalah olahraga aerobik yang intensitasnya tidak dapat dikendalikan dan pola gerakan lebih kompleks. Olahraga permainan misalnya bulutangkis, tennis, bola basket, sepakbola, dan lain-lain adalah olahraga aerobik tipe 3. Olahraga ini sangat tidak aman bagi lansia. Intensitas tidak dapat dikendalikan karena tergantung pada lawan main. Bila lawan main memiliki level permainan lebih rendah, maka bisa saja intensitas latihan rendah, tetapi bila lawan main memiliki level permainan lebih tinggi. maka intensitas bisa sangat meningkat (ACSM, 2006). 
Menghitung dan Mengukur Intensitas Latihan

Intensitas latihan adalah ukuran berapa banyak energi atau berapa berat usaha yang dikeluarkan ketika melakukan latihan. Parameter yang terbaik adalah dengan mengukur kalori namun hal ini sulit dilakukan. Oleh sebab itu dipergunakan cara lain yang lebih sederhana yaitu dengan menghitung laju jantung atau denyut nadi. Berdasarkan denyut nadi maka intensitas latihan dapat dikelompokkan ringan, sedang, berat. Intensitas latihan sedang bila denyut nadi berada pada kisaramn 50-85\% denyut nadi maksimal. Denyut nadi maksimal diperoleh dari rumus 220- usia. Bila usia 50 tahun, maka denyut nadi maksimal adalah 170. Dengan demikian kisaran denyut nadi untuk latihan intensitas sedang pada usia 50 tahun adalah $50 \%$ x $170-85 \%$ x $170=85-$ 145 denyut/menit (ACSM, 2006) (Tabel 1).

Tabel 1. Denyut nadi maksimal dan latihan intensitas sedang

\begin{tabular}{ccc}
\hline Usia & $\begin{array}{c}\text { Denyut nadi maksimal } \\
(\mathbf{2 2 0} \text {-usia) }\end{array}$ & $\begin{array}{c}\text { Denyut nadi latihan (60- } \\
\mathbf{8 5 \% )}\end{array}$ \\
\hline 50 & 170 & $85-145$ \\
55 & 165 & $83-140$ \\
60 & 160 & $80-136$ \\
65 & 155 & $78-132$ \\
70 & 150 & $75-128$ \\
75 & 145 & $73-123$ \\
80 & 140 & $70-119$ \\
\hline
\end{tabular}

Denyut nadi saat latihan harus dimonitor agar berada pada kisaran intensitas yang telah ditetapkan. Denyut nadi latihan dapat dimonitor secara sederhana dengan cara menghitung denyut nadi arteri Brachialis (di pergelangan tangan sisi luar) atau di arteri Karotis (di daerah leher) selama 1 menit. Pengukuran dapat dilakukan selama 10 detik (hasil dikalikan 6) atau selama 15 detik (hasil dikalikan 4). Contoh, bila selama 10 detik teraba denyut nadi sebanyak 17 maka denyut nadi 1 menit adalah 17 x 6=102/menit (Gambar 3).

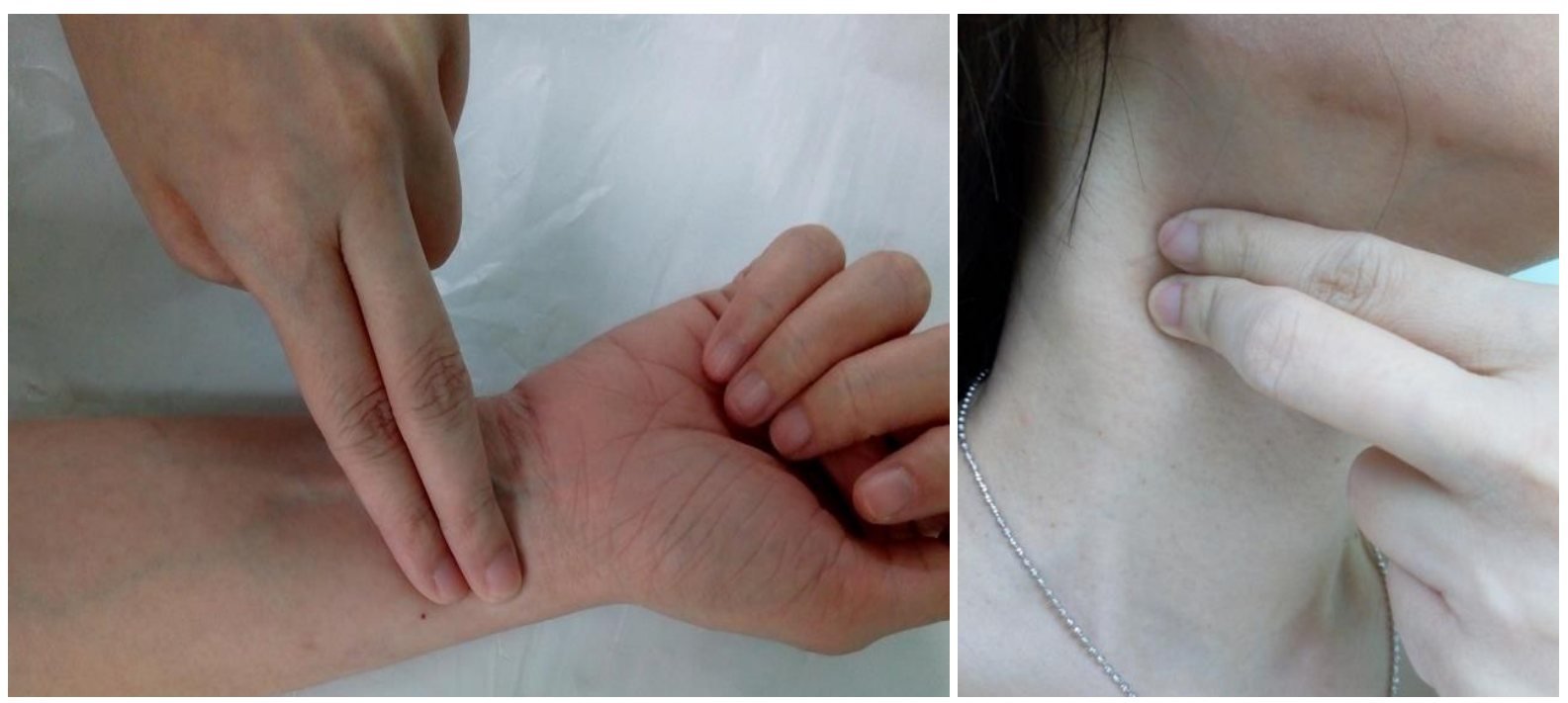

Gambar 3. Cara menghitung denyut nadi di pergelangan tangan dan leher. 
Olahraga Baik, Benar, Terukur, dan Teratur.

Baik artinya olahraga dilakukan terus menerus dimulai sejak usia dini, dilakukan di mana saja tetapi dengan memerhatikan kondisi lingkungan yang sehat, aman, nyaman, bebas polusi, dan tidak rawan cedera, serta menggunakan pakaian dan perlengkapan dengan yang sesuai dengan ukuran dan jenis olahraga.

Benar artinya olahraga atau latihan fisik disesuaikan dengan kemampuan atau kondisi kebugaran sehingga tidak menimbulkan efek yang merugikan, dan dilakukan secara bertahap, dimulai dari pemanasan, peregangan, latihan inti (20-60 menit), dan pendinginan.

Terukur artinya intensitas dapat diukur secara obyektif yaitu dengan menghitung denyut nadi atau dengan tes bicara (talk test). Bila saat berolahraga dapat berbicara tetapi dengan terngahengah maka intensitas olahraga atau latihan tersebut terlalu tinggi.

Teratur artinya olahraga dilakukan secara rutin dengan frekuensi $5 \mathrm{kali} /$ minggu. Dalam hal ini melakukan latihan atau olahraga perlu diperhatikan prinsip FITT (frekuensi, intensitas, time/durasi, dan tipe) (Pusdatin, Kemkes RI, 2015).

Tidak semua pertanyaan yang diajukan oleh peserta berhubungan dengan materi penyuluhan (Gambar 4). Beberapa peserta mengajukan pertanyaan tentang terapi medikasi bagi keluhan lututnya yang sudah lama tidak membaik. Beberapa peserta mengajukan pertanyaan berhubungan dengan masalah gizi. Kebetulan salah satu peserta penyuluhan adalah guru besar ilmu gizi Fakultas Kedokteran Universitas Indonesia sehingga pertanyaan terkait masalah gizi dapat dijawab oleh beliau.

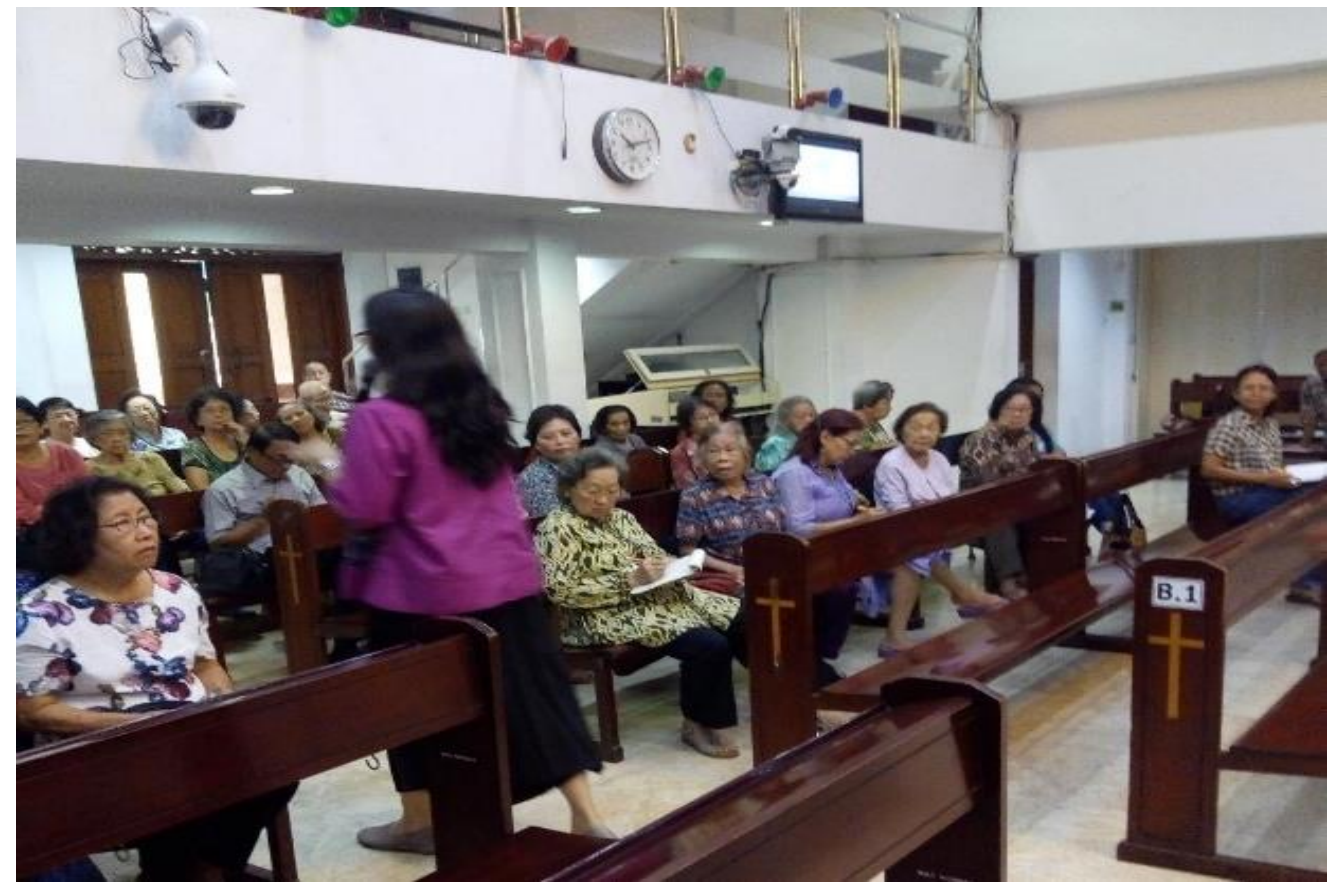

Gambar 4. Suasana penyuluhan.

Manfaat Latihan Fisik

Latihan fisik memiliki manfaat yang banyak. Bahkan latihan exercise dapat dianggap sebagai obat bagi kelompok lansia (Taylor, 2014). Manfaat terhadap kesehatan, latihan fisik dapat 
mencegah dan mengurangi obesitas, menurunkan tekanan darah, mencegah diabetes dan mengendalikan kadar gula darah, memperbaiki kadar lemak, mencegah penyakit jantung koroner, mencegah osteoporosis dan meningkatkan massa tulang, memerbaiki lingkup gerak sendi pada osteoartritis, dan mencegah terjadinya beberapa jenis keganasan. Manfaat terhadap mental, meningkatkan rasa percaya diri dan harga diri, meningkatkan kemampuan atensi, mengurangi kecemasan, menurunkan risiko depresi, mengurangi stress, dan memerbaiki kualitas tidur (Sharma, Madaan, Petty, 2006). Manfaat sosial, latihan fisik meningkatkan independensi, meningkatkan interaksi sosial, mencegah isolasi sosial dan rasa kesendirian, menurunkan kecenderungan melakukan kebiasaan antisosial, dan lain-lain (Physical Activity Task Force, 2012).

\section{KESIMPULAN DAN SARAN}

Olahraga sangat penting untuk meningkatkan kesehatan dan kebugaran bagi lansia. Latihan fisik memiliki manfaat terhadap kesehatan, mental, dan kehidupan sosial. Ada banyak pilihan jenis latihan fisik atau olahraga tetapi tidak semua sesuai dengan lansia. Jalan kaki adalah salah satu jenis latihan fisik yang paling sesuai untuk lansia. Namun demikian, jalan kaki harus dilakukan dengan teknik yang benar untuk menghindari cedera. Penyuluhan tentang teknik jalan yang benar sangat sesuai diberikan kepada kelompok lansia karena dapat meningkatkan manfaat dan meminimalisir risiko saat melakukan jalan kaki. Penyuluhan serupa mungkin dapat dilakukan dengan topik yang berbeda dan untuk kelompok lansia di tempat lain.

\section{Ucapan Terimakasih}

Ucapan terimakasih kami sampaikan kepada seluruh Pengurus Komisi Lansia GKI Nurdin yang telah memfasilitasi kegiatan ini hingga dapat terselenggara dengan baik.

\section{REFERENSI}

American College of Sports Medicine. (2006). ACSM's Guidelines for exercise testing and prescription. $7^{\text {th }}$ ed. Lippincott Williams \& Wilkins. Baltimore, Maryland.

de Oliveira, EP. \& Burini, RC. (2011). Food-dependent, exercise-induced gastrointestinal distress. Journal of International Society of Sports \& Nutrition, 8: 12. doi: 10.1186/15502783-8-12.

Garrick, JG. \& Requa, RK. (2003). Sports and fitness activities: the negative consequences. Journal of American Academy of Orthopaedic Surgeon, 11(6):439-43.

GBD 2015 Risk Factors Collaborators. (2016). Global, regional, and national comparative risk assessment of 79 behavioural, environmental and occupational, and metabolic risks or clusters of risks, 1990-2015: a systematic analysis for the Global Burden of Disease Study 2015. Lancet, 388(10053):1659-1724

Morton, DP. Richards, D. \& Callister, R. (2005). Epidemlology of exercise-related transient abdominal pain at the Sydney City to Surf community run. Journal of Science \& Medicine in Sport, 8(2):152-162.

Moses, FM. (1990). The effect of exercise on the gastrointestinal tract. Sports Medicine, 9(3):159-72.

Patelis, N. Karaolanis, G. Kouvelos, GN. Hart, C. Metheiken, S. (2016). The effect of exercise on coagulation and fibrinolysis factors in patients with peripheral arterial disease. Experimental Biology and Medicine, 241. doi:10.1177/1535370216660215.

Pauwels, N. (2012). Towards evidence based emergency medicine: Best BETs from the Manchester Royal Infirmary. BET 1: Is exercise-related transient abdominal pain (stitch) while running preventable? Emergency Medicine Journal, 29(11):930-931. 
Physical Activity Task Force. (2012). The co-benefits of physical activity. http://www.beactive.wa.gov.au/index.php?id=483.

Pusat Data dan Informasi. (2015). Pembinaan Kesehatan Olahraga di Indonesia. Kementerian Kesehatan www.depkes.go.id/download.php?file=download/pusdatin/infodatin/olahraga.pdf.

Scott, C. (2005). Misconceptions about Aerobic and Anaerobic Energy Expenditure. Journal of International Society of Sports \& Nutrition, 2(2): 32-37.

Sharma, A., Madaan, V., Petty, FD. (2006). Exercise for Mental Health. Prim Care Companion to the Journal of Clinical Psychiatry, 8(2): 106.

Szymanski, LM. \& Pate, RR. (1994). Effects of exercise intensity, duration, and time of day on fibrinolytic activity in physically active men. Medicine \& Science in Sports \& Exercise, 26(9):1102-1108.

Taylor, D. (2014). Physical activity is medicine for older adults. Postgraduate Medical Journal, 90:26-32.

U.S. Department of Health and Human Services. (2018). Physical Activity Guidelines for Americans. 2nd ed.. https://health.gov/paguidelines/second-edition.

WHO. (2009). Interventions on diet and physical activity: what works: summary report. Geneva, World Health Organisation. http://www.who.int/dietphysicalactivity/summary-report-09.pdf.

WHO. (2010). Global recommendations on physical activity for health. http://whqlibdoc.who.int/publications/2010/9789241599979_eng.pdf. 